\title{
Factors That Affect Recovery of Spontaneous Circulation by Patients With Cardiac Arrest Before Arrival at a Hospital in Daegu Metropolitan City, South Korea
}

Hyun-Ok Jung

Sangju of Correctional Institute

Seungwoo Han ( $\nabla$ qmflrjadud82@hanmail.net)

Kyungil University

\section{Research Article}

Keywords: Sudden cardiac arrest, Return of spontaneous circulation, Cardiopulmonary resuscitation, South Korea

Posted Date: April 16th, 2021

DOl: https://doi.org/10.21203/rs.3.rs-393200/v1

License: (c) (1) This work is licensed under a Creative Commons Attribution 4.0 International License. Read Full License 


\section{Abstract}

\section{Background}

This study was conducted to investigate the factors that influence Return of Spontaneous Circulation (ROSC) in patients who suffered cardiac arrest before arriving at the emergency room in DMC, Korea.

\section{Methods}

This study considered data for cardiac arrest patients by 119 paramedics from January 1, 2019 to December 31, 2019 in Daegu. Chi-squared analysis was conducted to analyze whether the subjects showed ROSC before arriving at the emergency room. Binary logic regression analysis was conducted to identify the factors that affect ROSC.

Results

ROSC when a mechanical compression device was used was reduced to 0.82 of that when it was not used $(95 \% \mathrm{Cl}=0.60 \sim 0.92)$. ROSC was 3.13 times higher when a first-aid defibrillator was used than when it was not used $(95 \% \mathrm{Cl}=1.40 \sim 6.99)$. ROSC was 657 times higher when epinephrine was injected than when it was not injected. Lastly, ROSC was $1.82(95 \% \mathrm{Cl}=1.04 \sim 3.19)$ times higher when intubation was used than when it was not used.

\section{Conclusion}

This study suggests that continuous CPR education, securing financial support, and expansion of emergency rooms for local residents are necessary.

\section{Background}

The death rate by Cardiovascular system disease in South Korea was 117.4 per 100,000 people in 2019. [1]. Sudden cardiac arrest (SCA) results in death with hemodynamic failure if the heart is not restarted within minutes [2]. In the United States, more than 550,000 patients suffer SCA each year before and during hospitalization, and SCA accounts for more than half of cardiovascular mortality, and is therefore a major concern for national interest and prevention [3]. The recovery rate of patients with cardiac arrest before arrival at the hospital in Korea increased by about 7 times from $1.1 \%$ in 2007 to $7.6 \%$ in 2017, but compared to advanced countries such as the US $11.4 \%$, Sweden $14.0 \%$, and Norway $13.0 \%$, the rate is still very low $[4,5]$. To solve the practical problems of emergency medical treatment, the Korean government has been actively studying the prevention and management of diseases by establishing cardiovascular and cerebrovascular prevention centers to consider the characteristics of each disease in Korea.

Daegu Metropolitan City (DMC) in southeastern Korea has the fourth-largest population (2.4 million) in the country. The number of emergency room deaths among emergency-room users in DMC was $0.418 \%$, 
which was the highest in the country, but the death rate before arrival in the emergency room was $0.05 \%$, which was the lowest in the country [7].

Considering the these opposing characteristics in the emergency medical situations in DMC, the factors that influence Return of Spontaneous Circulation (ROSC) in patients with cardiac arrest in pre-hospital, where and rapid response is required, may contribute to improvement of community participation and emergency care. Previous studies have shown that pre-emergency factors that are closely related to patient survival rate include whether the cardiac arrest patient was witnessed, whether witnesses performed CPR, whether electrocardiogram rhythm was defibrillable, and whether the ROSC occurred spontaneously [8,9]. However, the factors that affect ROSC have not been studied in depth by country or region. This lack occurs because the environment and resources of emergency medical care in each country are different, so the rapid treatment and methods of coping with patients who have pre-hospital cardiac arrest may also differ.

Rather than identifying the theoretically known factors that affect the ROSC, this study focuses on patient data applied by actual paramedic, and identifies factors that influence ROSC in the region in a practical and multifaceted manner, and thereby contributes to development of emergency medical services. Therefore, the goal of this study was to identify factors that can improve ROSC rate of prehospital cardiac arrest patients, and thereby provide basic data that can be exchanged between countries and contribute to development of emergency medical systems beyond the local community

The purpose of this study is to determine whether patients with cardiac arrest recovered their circulation spontaneously before arriving at an emergency room in DMC in 2019, and to determine the factors that affected this recovery. The specific purposes were: To identify whether or not spontaneous circulation is restored before a patient arrives at the emergency room, and to identify factors that affect ROSC before a patient's arrival in the emergency room.

\section{Methods}

\section{Study Setting}

This study considered data from patients with cardiac arrest treated by 119 paramedics from January 1 , 2019 to December 31, 2019 in DMC. For data collection, the purpose and suitability of the study was explained to the head of the DMC Fire Department, and the use of the data was approved.

The emergency activity log and the details of the cardiopulmonary arrest detailed situation table were anonymized. The total number of cardiac arrest procedures during the target period was 2750 . Among them, 1307 cases were selected for the ROSC; cases for which CPR was withheld or suspended by medical guidance of paramedics due to apparent death or other causes, were not considered.

\section{Data Collection}


This study selected and investigated items that are estimated to have an effect on ROSC, as suggested by the emergency-activity log and the detailed cardiopulmonary arrest schedule prepared by 119 paramedics.

The dependent variables were the ROSC of cardiac arrest patients; independent variables were the Type of occurrence, Place of occurrence, Whether the cardiac arrest was witnessed, Whether CPR was performed, Whether a mechanical compression device was used, Whether a first-aid defibrillator was used, Whether epinephrine had been administered intravenously, and Whether intubation was performed.

Specifically, ROSC was defined as (yes $=1$, no $=2$ ). The codes for independent variables were: Type of occurrence (disease $=1$, non-disease $=2$ ), Place of occurrence (house $=1$, ambulance $=2$, nursing institution (medical facility) $=3$, other $=4$ ), Whether the cardiac arrest was witnessed (Witnessed = 1 , not witnessed $=2$, unknown $=3$ ), Whether CPR was performed (performed $=1$, not performed $=2$, unknown $=$ 3), Whether a mechanical compression device was used (Used = 1, not used = 2), Whether a first-aid defibrillator was used (Used = 1, Not used = 2), Whether epinephrine had been administered intravenously (Secured = 1, Not secured $=2$ ), and Whether intubation was performed (Performed = 1, Not performed $=2$ ).

\section{Statistical Analysis}

In this study, IBM SPSS/WIN 23.0 Program was used for data analysis. Frequency analysis was used to quantify the general characteristics of the subjects, and Chi-squared analysis was conducted to analyze whether the subjects showed ROSC before arriving at the emergency room. Binary Logistic Regression Analysis was conducted to identify factors that affected ROSC.

\section{Ethical consideration}

The data in this study were approved and obtained from the emergency activity log and cardiopulmonary arrest detailed situation chart prepared by 119 paramedics at the DMC Fire Department, and obtained approval from K University Institutional Review Board (IRB) for the exemption of deliberation (IRB1041459-202103-HR-003-01).

\section{Results}

\section{General characteristics of out-of-hospital cardiac arrest patients}

Of the patients, $90.3 \%$ had a disease. Home (86.9\%) has the most frequent place of occurrence. Most of the cardiac arrests were not witnessed (69.9\%), and CPR was usually not performed (63.2\%).

Mechanical compression devices were generally not used (60.4\%), and first-aid defibrillators were generally not used (91.9\%). Epinephrine was generally not administered intravenously (68.3\%), and intubation was generally not performed (58.0\%) (Table 1). 


\section{Whether ROSC occurred before arriving at the emergency room according to characteristics related to the occurrence}

SROC before arriving at the emergency room was statistically more probable if the cardiac arrest was witnessed $(X 2=29.727, P<0.001)$, if $C P R$ was performed $(X 2=6.232, P=0.044)$, if a mechanical compression device was used $(X 2=95.596, P<0.001)$, if a first-aid defibrillator was used $(X 2=146.241$, $P<0.001)$, and if intravenous access was secured $(X 2=25.364, P<0.001)$ (Table 2$)$.

\section{Factors that influenced ROSC before arrival at the emergency room}

This study confirmed that the factors that affect ROSC before arrival at the emergency room were: use of a mechanical compression device, use of a first-aid defibrillator, administration of epinephrine, and use of intubation. Compared to cases in which the method was not used,

ROSC was reduced to 0.82 times when a mechanical compression device was used compared to when it was not used ( $95 \% \mathrm{Cl}=0.60 \sim 0.92) ; 3.13$ times higher when an electrical defibrillator was used (95\% $\mathrm{Cl}=1.40 \sim 6.99) ; 6.57$ times higher when intravenous access was used $(95 \% \mathrm{Cl}=2.16 \sim 19.53)$, and 1.82 times when intubation was used $(95 \% \mathrm{Cl}=1.04 \sim 3.19)$ (Table 3$)$.

\section{Discussion}

This study confirmed that the use of a mechanical compression device affects the probability of ROSC before the patient arrives at the emergency room. These findings show that use of a mechanical compression device was less effective than manual CPR in achieving ROSC. This result contradicts a prior study [11], which showed that mechanical compression devices were more effective than CPR in achieving ROSC, and with a review of 1,187 systems [12], which showed no significant difference between mechanical compression devices and hand CPR in achieving ROSC. This conflicting finding may be a result of the situational environment of the country, because paramedics in Korea they tend to prefer hand CPR over mechanical compression unless the ambulance ride is long. In addition, mechanical compression devices are not always available in ambulances nationwide in Korea. These observations indicate that active research and preparation for the use of mechanical compression devices is necessary in Korea. To increase the efficiency of the use of mechanical compression devices, appropriate training on teamwork and the use of these machines should be provided, but the difference in education level and scope of work for each paramedic raises another practical problem.

This study determined that use of a first aid defibrillator increased the ROSC by 3.13 times. A previous study [13] suggested that improvement of the quality of CPR and the availability of AEDs can improve the probability that a patient will survive heart failure. The latest ALS guidelines suggest that about $20 \%$ of patients with out-of-hospital cardiac arrests experience ventricular tachycardia or ventricular fibrillation [14]. In pre-hospital patients, especially during ventricular tachycardia or ventricular fibrillation, a reduction in the time before AED is applied increases the probability of obtaining ROSC [15]. This finding is consistent with the results of a study conducted only with cardiac arrest patients who had been treated 
using an AED, and that showed that defibrillation was possible $63.6 \sim 70.8 \%$ of the time, and that a high rate ROSC $[16,17]$. Therefore, early application of an AED to restore appropriate rhythms can achieve ROSC and contribute strongly to the survival rate of pre-hospital cardiac arrest patients.

This study also confirmed that intravenous administration of epinephrine increased the likelihood of ROSC before arrival at the emergency room. These findings were found in previous studies [18] that epinephrine injection during out-of-hospital cardiac arrest increases the probability of both ROSC and short-term survival. In general, epinephrine should be injected as soon as possible when arrhythmia does not respond to AED [19]. In another previous study [20], the average time before intravenous injection during cardiac arrest outside the hospital was 19.4 minutes. People who receive injected epinephrine as soon as possible (within $10 \mathrm{~min}$ ) are approximately 4.52 times more likely to show ROSC than those who receive it late (within $30 \mathrm{~min}$ ). Therefore, this study suggests that fast acquisition of intravenous access is an important factor that influences ROSC. These findings suggest that rapid treatment by paramedics is needed when pre-hospital cardiac arrest occurs, and that fast and skilled application of intravenous epinephrine is needed. However, paramedics have different proficiencies, so the probability of success applying intravenous epinephrine can vary. Korea is investing time and training for paramedics to secure skillful intravenous access, but the difference in skill levels of paramedics must be corrected. Finally, in this study, intubation increased the probability of ROSC before arrival in the emergency room. The latest ALS guidelines described several approaches to intubation during CPR; they should be applied step-by-step by considering patient factors and rescuer skills [14]. This conclusion implies that a suitable intubation method must be chosen for the patient by considering the skilled teamwork and communication of paramedics. The results of this study confirmed that intubation increased the probability of ROSC, but a previous study [14] suggested that attempting intubation at a pre-hospital site may cause interruption of CPR and may cause harmful hyperventilation. Therefore, the appropriateness of intubation should be discussed in the future.

\section{Limitations}

This study identified the factors affecting the ROSC before arrival in the emergency room by considering data of 2,750 people in one metropolitan area, so the results may not be full applicable to all of Korea.

\section{Future Research}

The results of this study suggest that factors that affect the ROSC before arriving at the emergency room for samples from all over Korea. The various independent variables that were identified to affect ROSC should be verified.

The effects of time on spontaneous circulation should be evaluated. For example, the relationship between the time to arrival at the emergency room and the probability of ROSC, and the relationship between the time to achieve intravenous access and the probability of ROSC.

\section{Conclusion}


The results of this study identified that the factors that affect ROSC before arriving at the emergency room include the use of mechanical compression devices, the use of first-aid defibrillators, application of epinephrine, and use of intubation. To increase the probability of ROSC before the patient arrives at the emergency room, the following suggestions shall be made. First, continuous CPR education should be provided for local residents. CPR education is being provided by region in Korea, but has not been implemented for the entire community. Therefore, expansion of the population and national support may improve the CPR capabilities of local residents. Increase in the number of emergency rooms is also necessary; this number tends to be proportional to the population, so their availability may be limited for residents who live in the outskirts of cities.

\section{Abbreviations}

ROSC: Recovery of spontaneous circulation; DMC: Daegu Metropolitan City, CPR: Cardiopulmonary resuscitation; AED: Automated External Defibrillator; ALS: Advance life support

\section{Declarations}

\section{Acknowledgements}

We would like to acknowledge DMC Fire Department for providing data for this study.

\section{Authors' contribution}

HSW participated in the conception and design of the research. HSW and JHO acquired and analyzed the data. HSW and JHO interpreted the results. HSW wrote the manuscript. All authors read the manuscript.

\section{Availability of data and materials}

The datasets generated during and analysed during the current study are not publicly available due to agency requests and personal privacy but are available from the corresponding author on reasonable request.

\section{Ethics approval and consent to participate}

The study was conducted in accordance with the international guidelines for human research protection as Declaration of Helsinki and was approved by the Institutional Review Board of the Kyungil University, Gyeongsan, Korea. (IRB No. 1041459-202103-HR-003-01) with the waiver of informed consent.

\section{Consent for publication}

Not applicable.

\section{Competing interests}


The authors declare that they have no competing interests

\section{Author details}

${ }^{1}$ Hyun-Ok Jung (First Author, ORCID:0000-0001-8502-0745), Psychiatric Mental Health Advanced Practice Nurse, Ph.D, Sangju of Correctional Institute, Korea, 130, Mokga 2-gil, Sabeol-myeon, Sangju-si, Gyeongsangbuk-do, 37123 Korea, juiris@korea.kr

${ }^{2}$ Seung-Woo Han (Corresponding Author, ORCID:0000-0001-9144-3285) Assistant professor, Ph.D, Department of Emergency Medical Technology, Kyungil University. Gamasilgil Hayangeup, Gyeongbuk 38428 Korea, email:swhan@kiu.ac.kr Tel:82-53-600-5691, Fax:82-53-600-5699

\section{References}

1. Statistics Korea. Annual report on domestic statistics by topic 2021. Retrieved from: https://kosis.kr/statisticsList/statisticsListIndex.do? menuld=M_01_01\&vwcd=MT_ZTITLE\&parmTabld=M_01_01\&outLink=Y\&entrType=

2. Webner D, Duprey KM, Drezner JA., Cronholm P, Roberts WO. Sudden cardiac arrest and death in United States Marathons. Med Sci Sports Exerc. 2012;44(10):1843-5. doi:

10.1249/MSS.0b013e318258b59a

3. Marijon E, Uy-Evanado A, Dumas F, Karam N, Reinier K, Teodorescu C, Narayanan K, Gunson K, Jui j, jouven $X$, Chugh SS. Warning symptoms are associated with survival from sudden cardiac arrest. Ann Intern Med. 2016;164(1):23-9. doi: 10.7326/M14-2342

4. Centers for Disease Control and Prevention. 2006-2017 Survey statistics for acute cardiac arrest, Issued by: Disease prevention center for chronic diseases. PHWR. 2018;11(51):1-34.

5. Roger VL, Go AS, Lloyd-Jones DM, Benjamin EJ, Berry JD, Borden WB, Bravata DM, Dai S, Ford ES, Fox CS, et al. Heart disease and stroke statistics-2012 update: a report from the American Heart Association. Circulation. 2012;125(1):1-219. doi:10.1161/CIR.0b013e31823ac046

6. Statistics Korea. Annual report on the population statistics 2021. Retrieved from: https://kosis.kr/statHtml/statHtml.do?orgld=202\&tblld=DT_202N_B4\&conn_path=I2

7. Korean National Legal Information Center. Law on emergency medical services 2019. Retrieved from:http://www.law.go.kr/LSW/eng/engLsAstSc.do? menuld $=1 \&$ dataCls $=$ IsAstSc\&cptOfiCd $=1352000 \#$ cptOf 11352000

8. Jacobs I, Nadkarni V, Bahr J, Berg RA, Billi JE, Bossaert L, Cassan P, Coovadia A, D’Este K, Finn J, et al. Cardiac arrest and cardiopulmonary resuscitation outcome reports: update and simplification of the Utstein templates for resuscitation registries: a statement for healthcare professionals from a task force of the International Liaison Committee on Resuscitation (American Heart Association, European Resuscitation Council, Australian Resuscitation Council, New Zealand Resuscitation Council, Heart and Stroke Foundation of Canada, InterAmerican Heart Foundation, Resuscitation 
Councils of Southern Africa). Circulation. 2004;110(21):3385-97. doi:

10.1161/01.CIR.0000147236.85306.15.

9. Perkins GD, Jacobs IG, Nadkarni VM, Berg RA, Bhanji F, Biarent D, Bossaert LL, Brett SJ, Chamberlain $D$, de Caen AR, et al. Cardiac arrest and cardiopulmonary resuscitation outcome reports: update of the Utstein Resuscitation Registry Templates for Out-of-Hospital Cardiac Arrest: a statement for healthcare professionals from a task force of the International Liaison Committee on Resuscitation (American Heart Association, European Resuscitation Council, Australian and New Zealand Council on Resuscitation, Heart and Stroke Foundation of Canada, InterAmerican Heart Foundation, Resuscitation Council of Southern Africa, Resuscitation Council of Asia); and the American Heart Association Emergency Cardiovascular Care Committee and the Council on Cardiopulmonary, Critical Care, Perioperative and Resuscitation”. Circulation. 2015;132(13):1286-300. doi:

10.1161/CIR.0000000000000144.

10. Wang PL, Brooks SC. Mechanical versus manual chest compressions for cardiac arrest. Cochrane Database Syst Rev.2018;8(8):CD007260.doi:10.1002/14651858.CD007260.pub4

11. Lee HJ. The effect of a mechanical chest compressions for out-of-hospital advanced cardiac life support. J Converg Inf Technol. 2019;9(11):227-33. doi:10.22156/CS4SMB.2019.9.11.227

12. Brooks SC, Hassan N, Bigham BL, Morrison LJ. Mechanical versus manual chest compressions for cardiac arrest. Cochrane Database Syst Rev. 2014;27(2):CD007260. doi:

10.1002/14651858.CD007260.pub3.

13. Viereck S, Møller TP, ErsbøII AK, Folke F, Lippert F. Effect of bystander CPR initiation prior to the emergency call on ROSC and 30 day survival: an evaluation of 548 emergency calls. Resuscitation. 2017;111:55-61. doi:10.1016/j.resuscitation.2016.11.020

14. Soar J, Deakin C, Lockey A, Nolan J, Perkins G. 2015 Resuscitation Guidelines,1-36. Retrieved from: https://www.resus.org.uk/library/2015-resuscitation-guidelines/guidelines-adult-advanced-lifesupport

15. Banerjee P, Ganti L, Stead T., Vera A E, Vittone R, Pepe PE. Every one-minute delay in EMS on-scene resuscitation after out-of-hospital pediatric cardiac arrest lowers ROSC by $5 \%$. Resuscitation Plus. 2021;5:100062.doi:10.1016/j.resplu.2020.100062

16. Lee JS, Lee HP, Shon YD, Ahn HC, Ko BY, Wang SJ. The study of an automated external defibrillator (AED) use by 119 rescuers in Gyeonggi-do.J Korean Soc Emerg Med. 2008;19(1):15-21.

17. Lee HH, Seo KS, Chung JM, Park JB, Ryoo HW, Kim JK, et al. Study of out-of-hospital cardiac arrest patients for whom 119 rescuers used an automated external defibrillator in the metropolitan area. $J$ Korean Soc Emerg Med. 2008;19(1):245-52.

18. Chiang WC, Chen SY, Ko PCl, Hsieh MJ, Wang HC, Huang EPC, Yang CW, Chong KM, Chen WT, Chen SY, et al. Prehospital intravenous epinephrine may boost survival of patients with traumatic cardiac arrest: a retrospective cohort study. Scand J Trauma Resusc Emerg Med. 2015;23(1):1-7.

19. Hansen M, Schmicker RH, Newgard CD, Grunau B, Scheuermeyer F, Cheskes S, Vithalani V, Alnaji F, Rea T, Idris $\mathrm{AH}$, et al. Time to epinephrine administration and survival from nonshockable out-of- 
hospital cardiac arrest among children and adults. Circulation. 2018;137(19):2032-40. doi: 10.1161/CIRCULATIONAHA.117.033067

20. Mauch J, Ringer SK, Spielmann N, Weiss M. Intravenous versus intramuscular epinephrine administration during cardiopulmonary resuscitation: a pilot study in piglets. Pediatr Anaesth. 2013;23(10):906-12. doi: 10.1111/pan.12149

\section{Tables}

Table 1. General characteristics of out-of-hospital cardiac arrest patients 


\begin{tabular}{|c|c|c|c|}
\hline Characteristics & Categories & Frequency & $\%$ \\
\hline \multirow[t]{2}{*}{ Occurrence type } & Disease & 1879 & 90.3 \\
\hline & Anything other than disease & 202 & 9.7 \\
\hline \multirow[t]{4}{*}{ Place of occurrence } & House (parking lot, yard) & 2034 & 86.9 \\
\hline & In an ambulance & 99 & 4.2 \\
\hline & $\begin{array}{l}\text { Nursing institution (medical } \\
\text { facility) }\end{array}$ & 101 & 4.3 \\
\hline & Other & 106 & 4.6 \\
\hline \multirow[t]{3}{*}{ Was the cardiac arrest witnessed? } & Witnessed & 722 & 26.3 \\
\hline & Not witnessed & 1922 & 69.9 \\
\hline & Unknown & 106 & 3.8 \\
\hline \multirow[t]{3}{*}{ Was CPR performed? } & Performed & 963 & 35.9 \\
\hline & Not performed & 1696 & 63.2 \\
\hline & Unknown & 25 & 0.9 \\
\hline \multirow{2}{*}{$\begin{array}{l}\text { Was a mechanical compression } \\
\text { device used? }\end{array}$} & Used & 856 & 39.6 \\
\hline & Not used & 1307 & 60.4 \\
\hline \multirow[t]{2}{*}{ Was a first-aid defibrillator used? } & Used & 223 & 8.1 \\
\hline & Not used & 2527 & 91.9 \\
\hline \multirow{2}{*}{$\begin{array}{l}\text { Was epinephrine administered } \\
\text { intravenously? }\end{array}$} & Secured & 380 & 31.7 \\
\hline & Not secured & 819 & 68.3 \\
\hline \multirow[t]{2}{*}{ Was intubation performed? } & Performed & 504 & 42.0 \\
\hline & Not performed & 695 & 58.0 \\
\hline \multirow[t]{2}{*}{ Was spontaneous circulation recovered? } & Yes & 187 & 14.3 \\
\hline & No & 1120 & 85.7 \\
\hline
\end{tabular}

Table 2. The characteristics related to ROSC 


\begin{tabular}{|c|c|c|c|c|}
\hline & \multirow[t]{2}{*}{ Categories } & \multicolumn{2}{|c|}{$\begin{array}{l}\text { Spontaneous recovery of } \\
\text { circulation }\end{array}$} & \multirow{2}{*}{$\chi^{2}(P)$} \\
\hline & & Yes & No & \\
\hline \multirow{2}{*}{$\begin{array}{l}\text { Acute cardiac arrest occurrence } \\
\text { type }\end{array}$} & Disease & 159 & 852 & \multirow{2}{*}{$\begin{array}{l}0.016 \\
(0.850)\end{array}$} \\
\hline & $\begin{array}{l}\text { Anything other than } \\
\text { disease }\end{array}$ & 9 & 46 & \\
\hline \multirow[t]{4}{*}{ Place of occurrence } & House (parking lot, yard) & 101 & 742 & \multirow{4}{*}{$\begin{array}{l}0.707 \\
(0.872)\end{array}$} \\
\hline & In an ambulance & 13 & 81 & \\
\hline & $\begin{array}{l}\text { Nursing institution } \\
\text { (medical facility) }\end{array}$ & 6 & 57 & \\
\hline & Other & 7 & 47 & \\
\hline \multirow{3}{*}{$\begin{array}{l}\text { Was the cardiac arrest } \\
\text { witnessed? }\end{array}$} & Witnessed & 122 & 490 & \multirow{3}{*}{$\begin{array}{l}29.7327 \\
(0.001)\end{array}$} \\
\hline & Not witnessed & 60 & 583 & \\
\hline & Unknown & 5 & 47 & \\
\hline \multirow[t]{3}{*}{ Was CPR performed? } & Performed & 117 & 616 & \multirow{3}{*}{$\begin{array}{l}6.232 \\
(0.044)\end{array}$} \\
\hline & Not performed & 57 & 450 & \\
\hline & Unknown & 1 & 14 & \\
\hline \multirow{2}{*}{$\begin{array}{l}\text { Was a mechanical compression } \\
\text { device used? }\end{array}$} & Used & 61 & 795 & \multirow{2}{*}{$\begin{array}{l}95.60596 \\
(0.001)\end{array}$} \\
\hline & Not used & 107 & 281 & \\
\hline \multirow{2}{*}{$\begin{array}{l}\text { Was a first-aid defibrillator } \\
\text { used? }\end{array}$} & Used & 89 & 132 & \multirow{2}{*}{$\begin{array}{l}146.241 \\
(0.001)\end{array}$} \\
\hline & Not used & 98 & 988 & \\
\hline \multirow{2}{*}{$\begin{array}{l}\text { Was epinephrine administered } \\
\text { intravenously? }\end{array}$} & Secured & 87 & 291 & \multirow{2}{*}{$\begin{array}{l}25.364 \\
(0.001)\end{array}$} \\
\hline & Not secured & 13 & 189 & \\
\hline \multirow[t]{2}{*}{ Was intubation performed? } & Secured & 80 & 422 & \multirow{2}{*}{$\begin{array}{l}4.456 \\
(0.052)\end{array}$} \\
\hline & Not secured & 20 & 58 & \\
\hline
\end{tabular}

Table 3. Factors influencing the ROSC 


\begin{tabular}{|c|c|c|c|c|c|}
\hline Characteristics & Categories & B & $\begin{array}{l}\text { Odds } \\
\text { ratio }\end{array}$ & $95 \% \mathrm{Cl}$ & $p$ \\
\hline \multirow[t]{2}{*}{ Occurrence type } & Disease & -0.18 & 0.84 & \multirow[t]{2}{*}{$0.159 \sim 4.430$} & \multirow[t]{2}{*}{0.836} \\
\hline & $\begin{array}{l}\text { Anything other than } \\
\text { disease }\end{array}$ & 1.00 & 1.00 & & \\
\hline \multirow[t]{4}{*}{ Place of occurrence } & $\begin{array}{l}\text { House (parking lot, } \\
\text { yard) }\end{array}$ & 0.70 & 2.01 & \multirow[t]{4}{*}{$0.04 \sim 50.73$} & \multirow[t]{4}{*}{0.305} \\
\hline & In an ambulance & -0.05 & 0.96 & & \\
\hline & $\begin{array}{l}\text { Nursing institution } \\
\text { (medical facility) }\end{array}$ & 1.35 & 3.86 & & \\
\hline & Other & 1.00 & 1.00 & & \\
\hline \multirow{3}{*}{$\begin{array}{l}\text { Was the cardiac arrest } \\
\text { witnessed? }\end{array}$} & Witnessed & 1.41 & 4.09 & \multirow[t]{3}{*}{$0.19 \sim 41.73$} & \multirow[t]{3}{*}{0.577} \\
\hline & Not witnessed & 0.66 & 1.93 & & \\
\hline & Unknown & 1.00 & 1.00 & & \\
\hline \multirow[t]{3}{*}{ Was CPR performed? } & Performed & -3.68 & 0.03 & \multirow[t]{3}{*}{$0.1 \sim 1.59$} & \multirow[t]{3}{*}{0.083} \\
\hline & Not performed & -3.55 & 0.03 & & \\
\hline & Unknown & 1.00 & 1.00 & & \\
\hline \multirow{2}{*}{$\begin{array}{l}\text { Was a mechanical } \\
\text { compression device used? }\end{array}$} & Used & -1.70 & 0.18 & \multirow[t]{2}{*}{$0.08 \sim 0.40$} & \multirow[t]{2}{*}{0.001} \\
\hline & Not used & 1.00 & 1.00 & & \\
\hline \multirow{2}{*}{$\begin{array}{l}\text { Was a first-aid defibrillator } \\
\text { used? }\end{array}$} & Used & 1.14 & 3.13 & \multirow[t]{2}{*}{$1.40 \sim 6.99$} & \multirow[t]{2}{*}{0.005} \\
\hline & Not used & 1.00 & 1.00 & & \\
\hline \multirow{2}{*}{$\begin{array}{l}\text { Was epinephrine administered } \\
\text { intravenously? }\end{array}$} & Secured & 1.88 & 6.57 & \multirow[t]{2}{*}{$2.16 \sim 19.53$} & \multirow[t]{2}{*}{0.001} \\
\hline & Not secured & 1.00 & 1.00 & & \\
\hline \multirow[t]{2}{*}{ Was intubation performed? } & Secured & 0.60 & 1.82 & \multirow[t]{2}{*}{$1.04 \sim 3.19$} & \multirow[t]{2}{*}{0.001} \\
\hline & Not secured & 1.00 & 1.00 & & \\
\hline
\end{tabular}

